\title{
Molecular basis of 'hypoxic' breast cancer cell radio-sensitization: phytochemicals converge on radiation induced Rel signaling
}

\author{
Sheeja Aravindan ${ }^{1}$, Mohan Natarajann ${ }^{2}$, Terence S Herman ${ }^{1}$, Vibhudutta Awasthi ${ }^{3}$ and Natarajan Aravindan ${ }^{\text {* }}$
}

\begin{abstract}
Background: Heterogeneously distributed hypoxic areas are a characteristic property of locally advanced breast cancers (BCa) and generally associated with therapeutic resistance, metastases, and poor patient survival. About $50 \%$ of locally advanced $\mathrm{BCa}$, where radiotherapy is less effective are suggested to be due to hypoxic regions. In this study, we investigated the potential of bioactive phytochemicals in radio-sensitizing hypoxic BCa cells.

Methods: Hypoxic (O2-2.5\%; N2-92.5\%; CO2-5\%) MCF-7 cells were exposed to 4 Gy radiation (IR) alone or after pretreatment with Curcumin (CUR), curcumin analog EF24, neem leaf extract (NLE), Genistein (GEN), Resveratrol (RES) or raspberry extract (RSE). The cells were examined for inhibition of NFkB activity, transcriptional modulation of $88 \mathrm{NFKB}$ signaling pathway genes, activation and cellular localization of radio-responsive NFKB related mediators, eNos, Erk1/2, SOD2, Akt1/2/3, p50, p65, plkBa, TNFa, Birc-1, -2, -5 and associated induction of cell death.

Results: EMSA revealed that cells exposed to phytochemicals showed complete suppression of IR-induced NFkB. Relatively, cells exposed EF24 revealed a robust inhibition of IR-induced NFKB. QPCR profiling showed induced expression of $53 \mathrm{NFkB}$ signaling pathway genes after IR. Conversely, 53, 50, 53, 53, 53 and 53 of IR-induced genes were inhibited with EF24, NLE, CUR, GEN, RES and RSE respectively. In addition, 25, 29, 24, 16, 11 and 21 of 35 IR-suppressed genes were further inhibited with EF24, NLE, CUR, GEN, RES and RSE respectively. Immunoblotting revealed a significant attenuating effect of IR-modulated radio-responsive eNos, Erk1/2, SOD2, Akt1/2/3, p50, p65, plkBa, TNFa, Birc-1, -2 and -5 with EF24, NLE, CUR, GEN, RES or RSE. Annexin V-FITC staining showed a consistent and significant induction of IR-induced cell death with these phytochemicals. Notably, EF24 robustly conferred IR-induced cell death.
\end{abstract}

Conclusions: Together, these data identifies the potential hypoxic cell radio-sensitizers and further implies that the induced radio-sensitization may be exerted by selectively targeting IR-induced NFkB signaling.

Keywords: Breast cancer, Hypoxia, Radio-sensitization, Phytochemicals, NFkB, Curcumin, EF24, Neem leaf extract, Genistein, Resveratrol, Raspberry extract

\section{Background}

Radiotherapy (RT) remains one of the prime treatment modality for breast cancer. It was established mainly in the 1990s that a low pre-treatment intra-tumoral partial oxygen pressure (pO2), as determined by needle electrode measurement, is associated with a poor outcome of treatment, in particular RT but also surgical treatment

\footnotetext{
*Correspondence: naravind@ouhsc.edu

'Department of Radiation Oncology, University of Oklahoma Health Sciences Center, Oklahoma City, OK, USA

Full list of author information is available at the end of the article
}

of several tumor types [1,2]. This association has been explained by the reduced ability of ionizing radiation (IR) to produce DNA damage in the absence of oxygen as well as, more recently, by an increased potential of hypoxic tumor cells for proliferation, invasion, metastasis and angiogenesis [3]. Consistently, studies have determined that poor tumor oxygenation is the strongest prognostic indicator of radiotherapy treatment outcome [4-6] and have indicated that breast tumor $\mathrm{pO}_{2}$ distribution prior to radiotherapy is sufficient to predict local response [7].

\section{Biomed Central}


Tissue hypoxia, an imbalance between oxygen delivery and oxygen consumption resulting in the reduction of oxygen tension below the normal level for a specific tissue [8], is a common feature of most solid tumors including breast carcinoma. This is partly due to the abnormal vascularization in tumors, which is insufficient in supplying $\mathrm{O}_{2}$ to the sometimes rapidly expanding malignant lesions. The use of polarographic $\mathrm{O}_{2}$ needle electrodes have revealed low $\mathrm{pO}_{2}$ values of $23-28 \mathrm{mmHg}$ (median) for tumors, as opposed to benign lesions $(42 \mathrm{mmHg})$ and normal tissue $(54-65 \mathrm{mmHg})$ [9,10]. Particularly, of all readings taken from breast cancers, $30-40 \%$ falls below $10 \mathrm{mmHg}$, which is very rarely seen in normal tissue $[9,10]$. Further, studies have revealed that nearly $40 \%$ of breast malignancies exhibit tumor regions with oxygen concentrations below that required for half-maximal radio-sensitivity $\left(\mathrm{pO}_{2}<2.5 \mathrm{mmHg}\right.$ ) [9]. To that end, for decades, investigators have attempted to overcome the treatment resistance of hypoxic tumors in clinical trials, for example by adding so-called 'hypoxic radio-sensitizer' drugs to the regimens or introducing hyperbaric oxygen. Although many of the individual trials were negative, a modern meta-analysis confirms the efficacy of hypoxiadirected treatments [11]. Consequently, recent research focusing on hypoxic responses and delineation of important regulators of hypoxia has clearly indicated that 'the hypoxia response' in tumors can be used to define novel treatment strategies [8]. The future arsenal of novel cancer therapies will most certainly include specific targeting of hypoxic process.

The presence and extent of the hypoxic tumor microenvironments have recently been shown to influence tumor progression by regulating both tumor cell survival and the expression of key angiogenic molecules. To that end, numerous studies have implicated the transcription factor, NFKB as a mediator of the hypoxic processes in tumor cells $[12,13]$. On the other hand, we and others have demonstrated a pronounced activation of $\mathrm{NF}_{\mathrm{K}} \mathrm{B}$ in response to IR in tumor cells including breast cancer cells [14-17]. NFKB is a member of the c-rel protooncogene family found within the promoter and enhancer region of a wide variety of cellular genes involved in proliferation, differentiation and cell cycle control $[18,19]$. Unlike other inducible transcription factors, a multitude of conditions and agents, including IR, can activate $\mathrm{NF}_{\mathrm{K} B}$ in cells. On activation, NFKB can stimulate various targeted late-response genes $[18,19]$, including those responsible for cell cycle control, oncogenic activation, [20], cell growth, differentiation and metastasis $[21,22]$. More importantly, studies have established the influence of NFKB in induced adaptive resistance, inflammatory and proliferation response [23-26]. Together with the fact that $\mathrm{NFkB}$ is able to regulate $>150$ genes, hypoxia induced NFKB signal transduction and activity may play a key role in transcriptional activation of these downstream targets that potentially regulate radio-sensitization.

A plethora of recent research has been focused on exploiting the pharmacologically safe, bioactive phytochemicals as potent radio-sensitizers in a number of tumor types including breast cancer. To that note, we have shown that nutraceuticals viz., curcumin (CUR), black raspberry extract (RSE), neem leaf extract (NLE) etc., regulate a number of potential molecular targets and potentiate radio-sensitization in neuroblastoma, pancreatic cancer and breast tumor systems [15,27-31]. Here in, we investigated the effects of CUR, curcumin analog EF24, NLE, Genistein (GEN), Resveratrol (RES) and RSE on the NFKB DNA-binding activity and NFKB signal transduction in hypoxic breast cancer cells exposed to IR. Furthermore, we elucxidated the effects of these bioactives in the activation and cellular localization of hypoxia-responsive NFKB related effectors including p53, Akt, Nos3, Erk1/2, SOD2, p50, p65, TNF $\alpha$, IAP1, IAP2 and Survivin. More importantly, we elucidated the efficacy of these compounds in potentiating IR induced hypoxic cell killing in this setting. In hypoxic breast cancer cells, CUR, EF24, NLE, GEN, RES and RSE resulted in the (i) complete suppression of IR-induced NFKB-DNA binding activity (ii) attenuation of IR-induced $N F_{\kappa} B$ signal transduction and target transcriptome, (iii) mitigation of IR-induced Akt,, Nos3, Erk1/2, SOD2, p50, p65, TNF $\alpha$, Birc 1, 2 and 5 and (iv) potentiates IR-induced cell killing, implying that these bioactive phytochemicals may play a key role in regulating $\mathrm{NF}_{\mathrm{K}} \mathrm{B}$ signaling pathway dependent 'hypoxic processes' and may potentiate RT in this setting.

\section{Methods}

\section{Cell culture}

Estrogen receptor positive human adenocarcinoma (MCF-7) breast cancer cells were maintained as monolayer cultures by weekly serial passage in $100 \mathrm{~mm}$ tissue culture plates in Dulbecco's Modified Eagle medium (Cellgro, Herndon, VA) with $44 \mathrm{mM}$ sodium bi-carbonate, $4 \mathrm{mM}$ L-glutamine, supplemented with $10.2 \mathrm{IU} / \mathrm{ml}$ penicillin $/ 10.2 \mathrm{mg} / \mathrm{ml}$ streptomycin, and 10\% heat-inactivated fetal bovine serum (Atlanta Biological, Lawrence Ville, GA). When in exponential growth, the cells were observed to have a doubling time of approximately 16-18 h. For passage and for all experiments, the cells were detached using trypsin (0.25\%)/EDTA (1\%), re-suspended in complete medium, counted electronically using Countess Cell counter (Life Technologies Corp.) and incubated in a 95\% air/5\% CO2 humidified incubator.

\section{Hypoxia, phytochemicals treatment and Irradiation experiments}

The cells plated in $100 \mathrm{~mm}$ tissue culture plates containing $6 \mathrm{ml}$ of complete growth medium were allowed to grow up 
to $70-80 \%$ confluence. Then the cells were made quiescent by serum starvation overnight followed by treatment. For growth under hypoxia, the cells were incubated at $37^{\circ} \mathrm{C}$ in a modular chamber flushed with $2.5 \% \mathrm{O}_{2}, 5 \% \mathrm{CO}_{2}$ and 92.5\% $\mathrm{N}_{2}$. For phytochemical studies, $2.0 \mu \mathrm{g} / \mathrm{ml}$ RSE [27,31], 100nM CUR [15,29,31], 0.1\% NLE [30,31], 200nM EF24 [32], $100 \mu \mathrm{M}$ GEN and $100 \mu \mathrm{M}$ RES was added to the medium for $1 \mathrm{~h}$ before hypoxia. For IR experiments, the cells were irradiated with one single high dose (SDR-4 Gy) using Gamma Cell 40 Exactor (Nordion International Inc, Ontario, Canada) at a dose rate of $0.81 \mathrm{~Gy} / \mathrm{min}$. Mock irradiated cells were treated identical except that the cells were not subjected to IR. The experiments were repeated at least three times in each group. In all the groups the cells were harvested $24 \mathrm{~h}$ after IR.

\section{Electrophoretic mobility shift assay}

Nuclear protein extraction and electrophoretic mobility shift assay for $\mathrm{NF \kappa B}$, were performed as described in our earlier studies [33]. Autoradiograms were overexposed to portrait the inhibitory effect below constitutive level. Densitometry analysis was performed using a BioRad Multi-Analyst software package with an integrated density program. Group-wise comparisons were made using ANOVA with Tukey's post-hoc correction. A P value of $<0.05$ is considered statistically significant. For the competition assay, the nuclear extract was pre-incubated with unlabeled homologous $\mathrm{NFKB}$ oligonucleotide followed by addition of $\left[\gamma^{-32} \mathrm{P}\right]$-ATP labeled NFkB probe. Super shift analysis was performed as described earlier [33].

\section{Real-Time QPCR profiling of NFKB signaling pathway molecules}

Total RNA extraction and real-time QPCR profiling were performed as described in our earlier studies $[33,34]$. We used human $\mathrm{NF}_{\kappa} B$ signaling pathway profiler (Realtimeprimers.com, Elkins Park, PA) containing 88 genes representing 8 functional groups

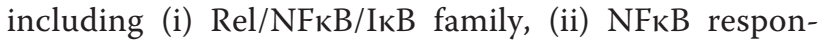
sive genes, (iii) Ligands \& Transmembrane receptors, (iv) Adaptor proteins, (v) Signal transduction kinases, (vi) Transcription factors, (vii) Cell death/survival molecules, and (viii) Other factors. We started with this highly selected QPCR profiler instead of an allencompassing gene array because the selected genes entail a well-characterized profile governing $\mathrm{NFKB}$ signal transduction and transcriptional targets, hence facilitating interpretation of data, simplifying data acquisition and analysis, and avoiding genes not functionally characterized. Furthermore, QPCR profiling allows detection and quantification of gene expression in real-time. Each profiling plate was also equipped with reverse transcription control, positive PCR control, genomic DNA control and five housekeeping genes - $\beta$-Actin, GAPDH, Rpl13a, HPRT1 and $\beta 2 M$. The $\Delta \Delta^{\mathrm{ct}}$ values were calculated by normalizing the gene expression levels to the expression of the housekeeping genes. The normalized data were then compared between groups, and the relative expression level of each gene was expressed as fold change.

\section{Immunoblotting}

Total protein extraction and immunoblotting were performed as described in our earlier studies [33]. Rabbit polyclonal anti-Birc1, 2, 5, eNOS, SOD2, AKT1/2/3, TNFo, p53, pAKT1/2/3 (all obtained from Santa Cruz Biotechnology Inc., Santa Cruz, CA), p50, p65 (obtained from Abcam, Cambridge, MA), ERK1/2 (Cell Signaling Technology, Danvers, MA), mouse monoclonal antipERK1/2 (Cell Signaling), pIкB $\alpha$ (Santa Cruz) and, goat polyclonal anti-peNOS (Santa Cruz) antibodies were used to detect the respective protein expression and phosphorylation levels in response to hypoxia and IR in conjunction with different phytochemicals. Blots were stripped and reprobed with mouse monoclonal anti$\alpha$-tubulin antibody (Santa Cruz) to determine equal loading of the samples. 1D gel analysis was performed using a BioRad Multi-Analyst software package with an integrated density program. Group-wise comparisons were made using ANOVA with Tukey's post-hoc correction. A P value of $<0.05$ is considered as statistically significant.

\section{Annexin- $\mathrm{V}$ binding assay}

The apoptotic events was quantified by the binding of Annexin- $\mathrm{V}$ to the externalized protein, phosphatidylserine, on the cell membrane during apoptosis with the ApoScreen Annexin V-Fluorescein (FITC) Kit (Southern Biotech, Birmingham, AL), according to the manufacturer's instructions. Briefly, the floating and trypsinized-adherent of hypoxic and untreated cells with or without IR and/or phytochemicals were collected and washed with PBS. Cells were resuspended in $1 \mathrm{X}$ binding buffer to a concentration of $1 \times 10^{7}$ cells $/ \mathrm{ml}$ were then stained with $10 \mu \mathrm{L}$ of Annexin V-FITC and $5 \mu \mathrm{l}$ of propidium iodide $(50 \mu \mathrm{g} / \mathrm{ml})$ for $15 \mathrm{~min}$ on ice, protected from light. Cells were analyzed using FACS Calibur flow cytometer equipped with a $488 \mathrm{~nm}$ argon laser and gated on viable cells by light scatter. Group-wise comparisons were made using ANOVA with Tukey's post-hoc correction. A P value of $<0.05$ is considered as statistically significant.

\section{Results}

Nutraceuticals impede IR-induced p50/p65 expression and DNA-binding activity in hypoxic BCa cells

To delineate the effect of IR on NFKB expression and DNA-binding activity in hypoxic breast cancer cells and further to elucidate the efficacy of nutraceuticals in this setting, human $\mathrm{BCa}$ (MCF-7) cells cultured under hypoxic conditions were either mock-irradiated or exposed to IR 
(2 Gy) with or without EF24, NLE, CUR, GEN, RES and RSE pre-treatment and harvested after 24 h post-IR. Compared to cells grown under normoxia, EMSA revealed a significant induction $(300.3 \pm 71.6 \%)$ of NFkB-DNA binding activity in hypoxic BCa cells (Figure 1A). Further, exposure of hypoxic cells to IR resulted in a robust $(813.7 \pm 216.5)$ induction of NFKB DNA-binding activity. On the other hand, we observed a consistent and complete inhibition of this IR-induced DNA-binding activity in EF24 (6.2 $\pm 4.0 \%)$, NLE (52.5 $\pm 11.3 \%)$, CUR (24.4 $\pm 4.9 \%)$, GEN (43.8 \pm 9.1$)$, RES $(36.9 \pm 7.7 \%)$ and RSE $(24.8 \pm 5.3 \%)$ pre-treated hypoxic
MCF-7 cells. More importantly, an assiduous inhibitory potential of these nutraceuticals was evident with NFkBDNA binding levels lesser than that of normoxic-mock-IR cells (Figure 1B). Consistently, western blot analysis from the nuclear extract revealed a significant induction of NFkB p50 and p65 levels in hypoxic BCa cells (Figure 1C). This hypoxia induced nuclear translocation of p50 and p65 is further enhanced with IR-exposure. More importantly, EF24, NLE, CUR, GEN, RES and RSE significantly reverted the IR-induced p50/p65 nuclear translocation in this setting (Figure $1 \mathrm{C} \& \mathrm{D})$. On the other hand, we observed an
(A)

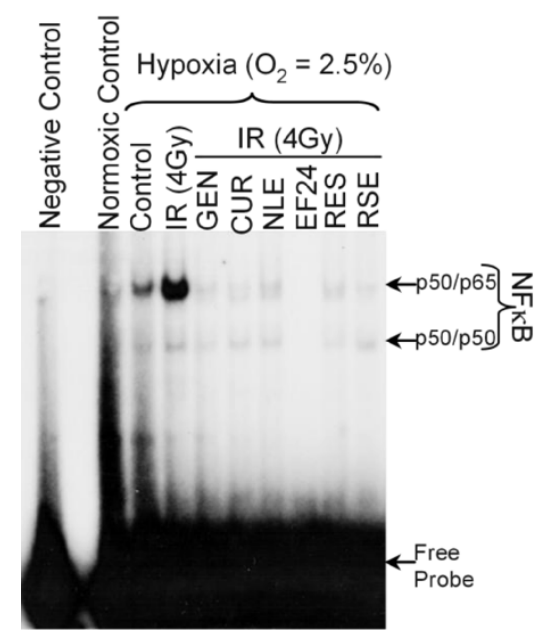

(C)
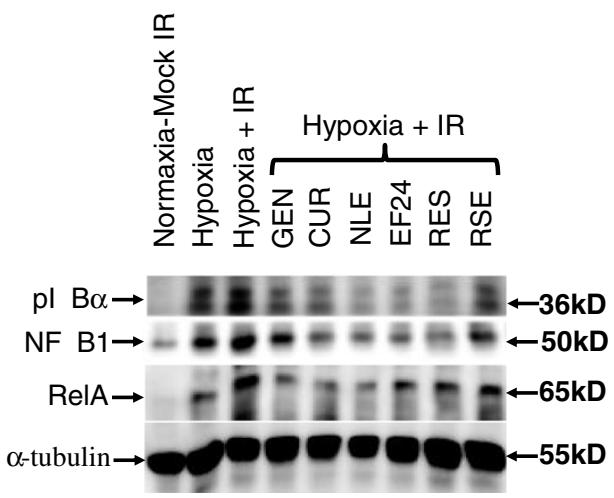

(B)

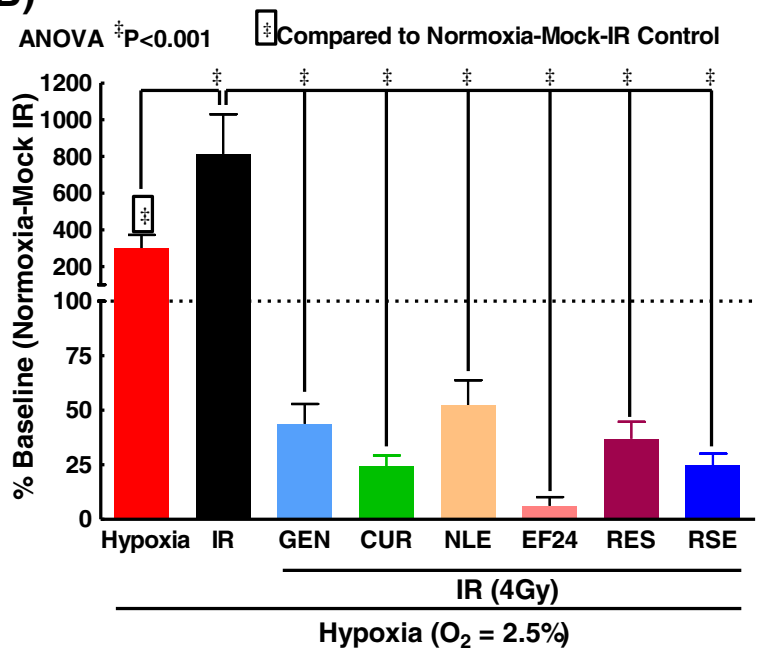

(D)

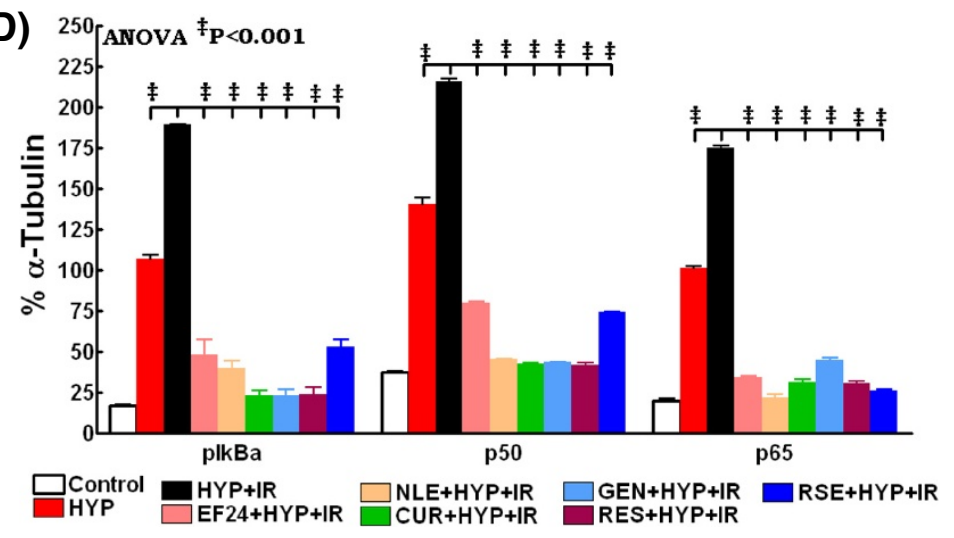

Figure 1 (A) A representative autoradiogram showing NFKB DNA-binding activity levels in MCF-7 cells exposed to hypoxia and/or radiation with or without EF24, NLE, CUR, GEN, RES or RSE pre-treatment. The nuclear extracts were analyzed by EMSA using $\gamma^{-}{ }^{32} p$ [ATP] labeled NFKB-specific probe. Compared to the normoxia controls, hypoxic cells showed a significant induction of NFKB-DNA binding activity. IR-exposure further enhanced hypoxia induced NFKB activity. Hypoxic cells treated with EF24, NLE, CUR, GEN, RES or RSE showed a significant inhibition of IR-induced NFKB-DNA binding activity. (B) Semi-quantitative densitometric analysis showing the effect of EF24, NLE, CUR, GEN, RES or RSE on IR-induced NFKB-DNA binding activity in hypoxic MCF-7 cells. (C) Western blot analysis showing modulation in the IKBa phosphorylation, nuclear translocation of NFKB p50 and p65 in hypoxic MCF-7 cells exposed to IR with or without EF24, NLE, CUR, GEN, RES or RSE treatment. Total cell extracts for plkBa and nuclear extracts for p50 and p65 were used.a-tubulin expression was determined to validate equal sample loading. (D) Histograms of densitometric analysis normalized to a-tubulin expression showing complete inhibition of IR-induced IKBa phosphorylation and nuclear translocation of p50/p65 in hypoxic BCa cells with EF24, NLE, CUR, GEN, RES or RSE treatment. Group-wise comparisons were made using two-way ANOVA with Tukey's post-hoc correction. 
induced I $\mathrm{K} \mathrm{B} \alpha$ phosphorylation in $\mathrm{BCa}$ cells grown under hypoxic conditions, which was further enhanced when the cells were exposed to IR (Figure 1D). However, a consistent inhibition of $I_{\kappa} B \alpha$ phosphorylation in hypoxic cells pretreated with EF24, NLE, CUR, GEN, RES or RSE and exposed to IR was evident (Figure 1D). These results correlated well with the $\mathrm{NF \kappa B}$ data which together validates the regulation of $\mathrm{NF} \mathrm{B} B$ in response to hypoxia and radiation with or without nutraceuticals.

\section{Nutraceuticals targets NFKB signaling transcriptome in} hypoxic breast cancer cells

Further to substantiate that bioactive nutraceuticals intervene IR-induced $\mathrm{NF} K \mathrm{~B}$ signaling in hypoxic cells, MCF-7 cells cultured under hypoxic conditions were either mock-irradiated or exposed to IR (2 Gy) with or without EF24, NLE, CUR, GEN, RES and RSE pre- treatment and harvested after $3 \mathrm{~h}$ post-IR. Custom QPCR profiling of $88 \mathrm{NF \kappa B}$ upstream/downstream signal transduction pathway molecules revealed that clinically relevant doses of radiation significantly induced 53 genes (Figure 2) and suppressed another 35 genes in hypoxic breast cancer cells. To that end, IR robustly increased the transcription of $N_{F} \mathrm{~B}$ family molecules including Rel, RelA, RelB, IKK $\beta$ and IKK $\gamma$ and, serves as the positive controls for the study. Interestingly, presence of nutraceuticals in the system completely and comprehensively reverted this IR-induced NFKB signal transduction in hypoxic cells. Treatment with EF24, CUR, GEN, RES and RSE resulted in complete suppression of all 53 IR-induced NFKB signal transduction genes in these cells under hypoxic conditions. NLE reverted 50 of 53 IR-induced genes in this setting (Figure 2). Evidently, all the nutraceuticals investigated revealed a

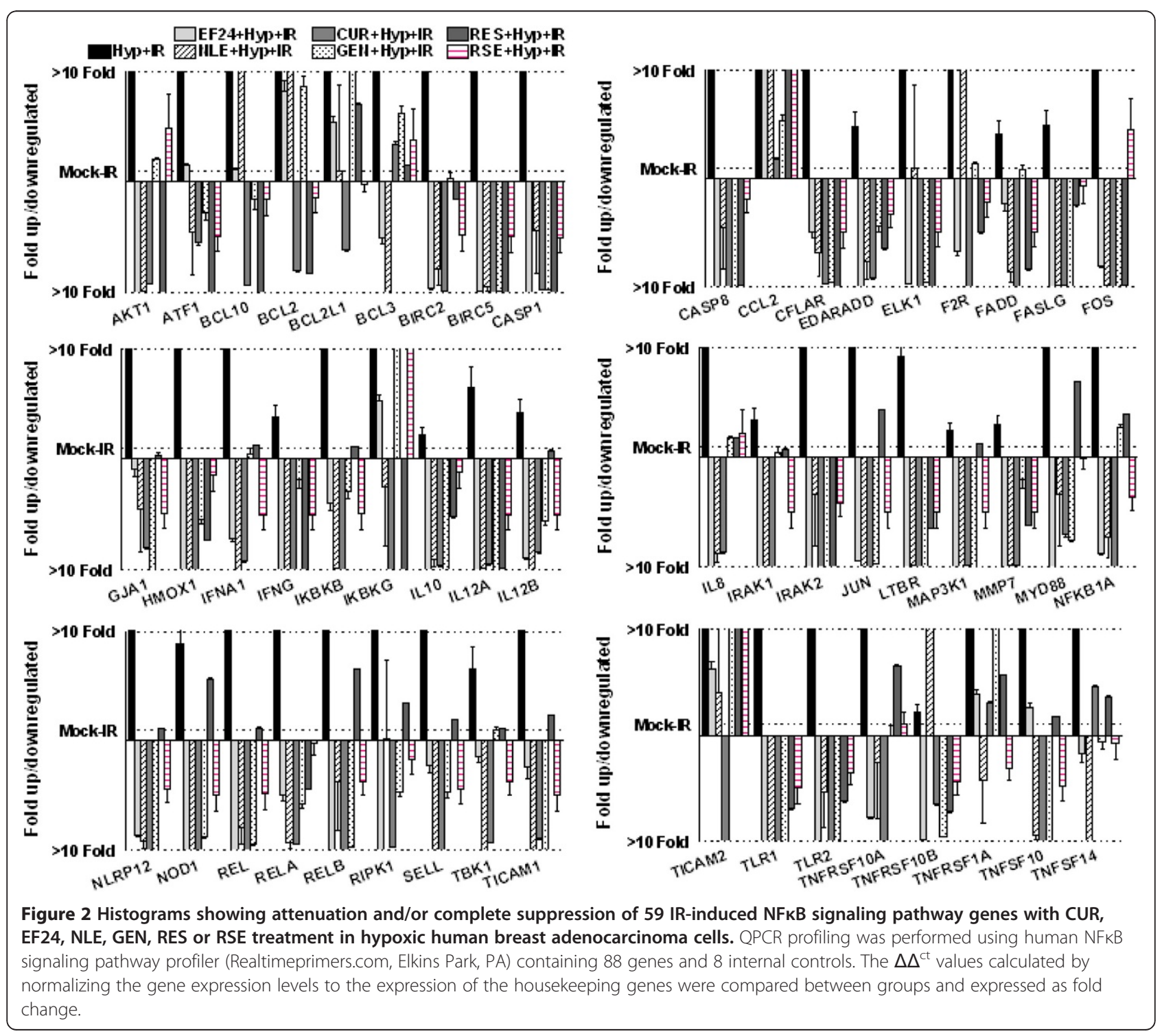


strong potential for the inhibition of Rel family molecules. Altogether, 50 of 53 IR-induced NFkB signaling pathway genes were targeted in common with EF24, NLE, CUR, GEN, RES and RSE. Conversely, IR-exposure resulted in the inhibition of $35 \mathrm{NF} \mathrm{B}$ signaling pathway genes as opposed to hypoxia alone. Notably, EF24, NLE, CUR, GEN, RES and RSE treatment further conferred $25,29,24,16,11$ and 21 of those IR-suppressed genes. Of these, five genes including $C s f 1, N F_{\kappa} B 2, P P M 1 A$, $R A F 1$ and $R H O A$ were commonly conferred after all nutraceuticals investigated.

Nutraceuticals reverts IR-altered cellular localization and/ or activation of NFKB signaling pathway proteins in hypoxic breast cancer cells

To confirm further that the bioactive EF24, NLE, CUR, GEN, RES and RSE targeted NFkB signaling pathway transcriptome is in fact translated into the $\mathrm{NF} \kappa \mathrm{B}$ signal transduction, we examined the alterations in both the cellular levels and activation of certain select NFKB upstream (AKT, ERK, eNOS), downstream (Birc 1, 2, 5) and, bifunctional (TNF $\alpha$, SOD2) signal transduction/effector proteins (Figure 3A). Compared to normoxic conditions, TNF $\alpha$ and SOD2 immunoblotting revealed a profound increase $(\mathrm{P}<0.001)$ in hypoxia treated cells. This hypoxia induced induction of both TNF $\alpha$ and SOD2 was significantly enhanced when the cells were exposed to IR (Figures 3A \& B). However, pretreating the cells either with EF24, NLE, CUR, GEN, RES or RSE completely $(\mathrm{P}<0.001)$ knock down this hypoxia and/or IR-activated TNF $\alpha$ and SOD2 in human MCF-7 cells (Figure 3B). Consistently, we observed an impetuous increase in $\mathrm{NF} \kappa \mathrm{B}$ direct downstream targets including Birc 1, 2 and 5 in cells exposed to hypoxia. Radiation on the other hand, significantly reduced the expression of these Bircs in the hypoxic cells. Nevertheless, EF24, NLE, CUR, GEN, RES or RSE treatment in conjunction with IR completely $(\mathrm{P}<0.001)$ knocked down these $N F \kappa B$ dependent pro-survival Birc 1, 2 and 5 in hypoxic cells (Figures 3A \& B). Analyzing the expression and phosphorylation of $\mathrm{NF} B \mathrm{~B}$ upstream signal transducing AKT, ERK and eNOS conform our transcriptome profiling data. Interestingly, induced expression levels of AKT1/2/3 in response to hypoxia and
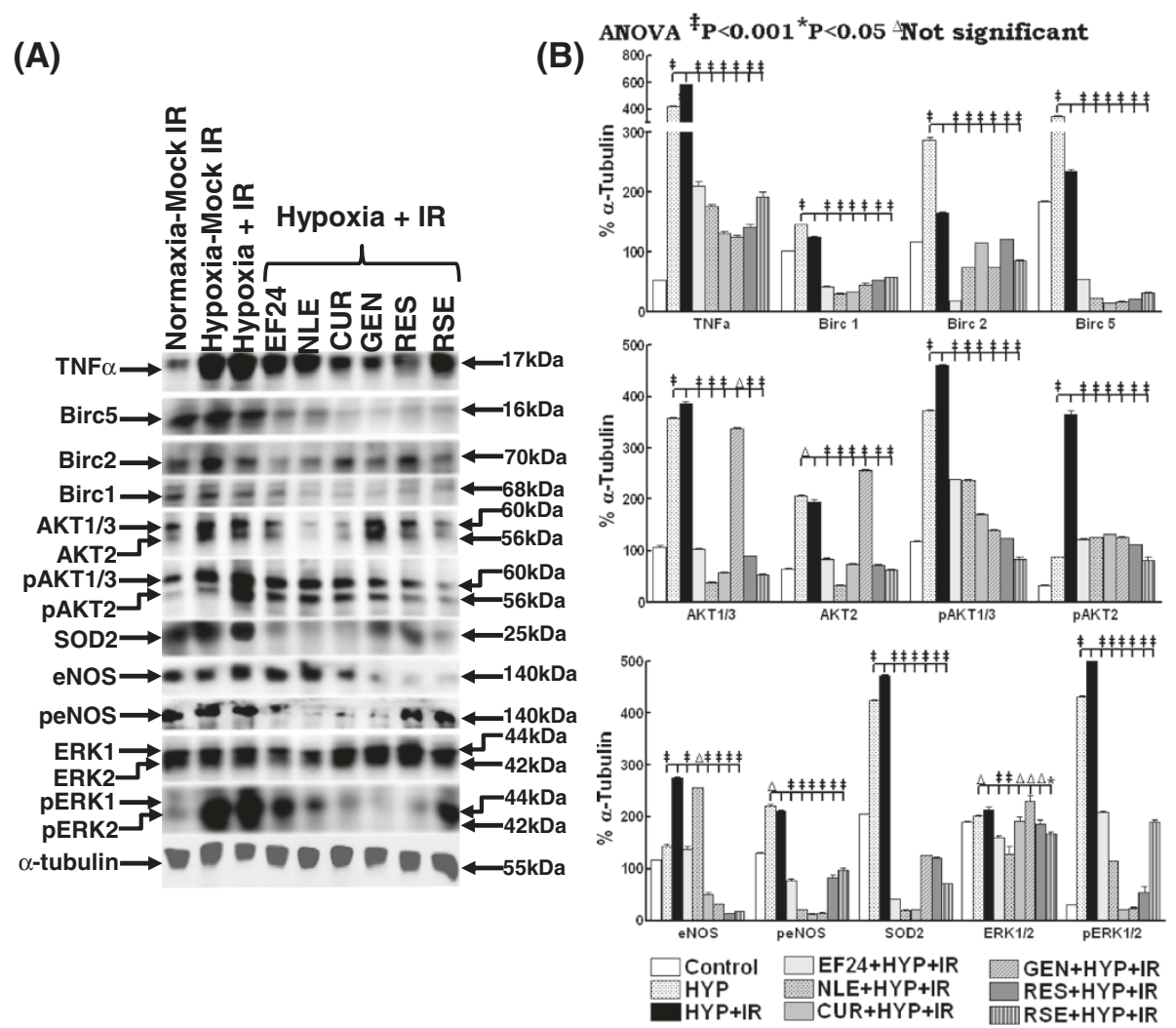

Figure 3 (A) Western blot analysis showing modulation in TNFa, Birc 1, 2, 5, SOD2, constitutive and phosphorylation of eNOS, AKT1/2/3 and ERK1/2 in hypoxic MCF-7 cells exposed to IR with or without EF24, NLE, CUR, GEN, RES or RSE treatment. a-tubulin expression was determined to validate equal sample loading. (B) Histograms of densitometric analysis normalized to a-tubulin expression showing complete inhibition of hypoxia and IR-induced TNFa, Birc 1, 2, 5, SOD2, and phosphorylation of eNOS, AKT1/2/3 and ERK1/2 in hypoxic BCa cells with EF24, NLE, CUR, GEN, RES or RSE treatment. Group-wise comparisons were made using two-way ANOVA with Tukey's post-hoc correction. 
further with IR exposure were evident in these cells. In parallel, hypoxia in the system instigated a robust ( $>4$ fold) phosphorylation of AKT1/2/3. Notably, this hypoxia induced AKT1/2/3 phosphorylation was further $(\mathrm{P}<0.001)$ influenced with IR-exposure. More importantly, EF24, NLE, CUR, RES or RSE completely mute both the IR-induced cellular levels and phosphorylation of AKT1/2/3 in the hypoxic cells (Figures $3 \mathrm{~A} \& \mathrm{~B}$ ). GEN on the other hand showed either no effect or increase in the cellular expression of AKT1/2/3. However, consistent with other bioactives, we observed a significant inhibition of IR-induced AKT1/2/3 phosphorylation in these hypoxic cells. Furthermore, hypoxia resulted in the relative increase in the constitutive eNOS and significant increase in the phosphorylation of eNOS. Interestingly, we did not see any further increase in eNOS phosphorylation with IR exposure. Conversely, EF24, NLE, CUR, GEN, RES or RSE treatment resulted in complete suppression of the hypoxia and/or IR altered eNOS phosphorylation (Figures 3A \& B). In addition, we observed a significant and robust increase in the ERK1/2 phosphorylation after hypoxia. Radiation evidently influenced further phosphorylation of ERK1/2 in these hypoxic cells. Consistent with the AKT and eNOS phosphorylation muting observed, we observed a total inhibition of ERK1/2 phosphorylation in EF24, NLE, CUR, GEN, RES or RSE treated cells (Figures $3 \mathrm{~A} \& \mathrm{~B}$ ).

EF24, NLE, CUR, GEN, RES and RSE confers IR-induced cell death in hypoxic breast cancer cells

To determine whether the bioactives targeting NFKB signaling cascade is in fact translates to functional response and to elucidate the radio-potentiating effect of these drugs in hypoxic conditions, we examined the alterations in induced cell death in hypoxic cells exposed to IR with or without EF24, NLE, CUR, GEN, RES or RSE treatment (Figure 4A \& B). Opposed to mock-IR hypoxic cells, IR exposure significantly induced $(\mathrm{P}<0.01)$ cell death in cells under hypoxia. However, coherent with our NFKB data, this IR-induced cell death is profoundly influenced in cells treated with EF24, NLE, CUR, GEN, RES or RSE (Figure 4B). Relatively, novel synthetic monoketone of curcumin, EF24 instigate more radiopotentiating effect as evident with the robust $(\mathrm{P}<0.001)$ cell death.

\section{Discussion}

Radiotherapy is very effective in local control of cancerous tumors, but its curative potential is often limited by intrinsic radio-resistance of the tumor cells. Hypoxia is one such limiting factor and indeed a main factor in most tumors including breast cancer that affects the radio-therapeutic ratio. Tumors tend to outgrow their blood supplies and develop hypoxic regions that preferentially protect tumor cells from radiation-induced DNA damage, as oxygen not only fixates DNA damage but also increases the number and complexity of DNA lesions produced by radiation. It has been shown that hypoxia can alter the biological state of tumor cells, including the transcription and translation of various proteins involved in cell survival [35]. Variety of metabolic stress signals including hypoxia activates NFKB $[13,36]$, that rapidly transduce hypoxic signals and facilitates the rapid control of many genes. Mechanisms involved in hypoxia induced $\mathrm{NF}_{\kappa} \mathrm{B}$ is discussed in detailed elsewhere [37]. Since hypoxia can induce $N F \kappa B$ activation, this pathway may contribute to a pro-malignant phenotype not only by promoting cell proliferation and survival, but also by upregulating gene products that control cell adhesion and angiogenesis. To that note, though a number of studies have identified the possible role of $\mathrm{NF} \kappa \mathrm{B}$ dependent downstream response in hypoxic processes, a definitive insight on the regulation of $\mathrm{NFKB}$ signaling in response to hypoxia in breast cancer, if not in any tumors is still at vague. Moreover, how this hypoxia associated $\mathrm{NF}_{\kappa} \mathrm{B}$ response translates after any prime therapeutic intervention is not understood. To our knowledge, this is the first attempt to characterize NFKB signaling in hypoxic breast cancer cells in response to a treatment modality, here in this case, radiotherapy and, further to delineate the modulation of altered signaling response to known anti-tumor phytochemicals. Consistent with the published evidence [13,36,38], hypoxia resulted in significant induction of $N F \kappa B$ activity and serves as the positive controls for the study. In addition, the results also add on a new insight on the altered NFKB signaling pathway transcriptome modulation in response to hypoxia in these cells. However, for the first time, this study identified that the radiation instigated pronounced $\mathrm{NF}_{\mathrm{K}} \mathrm{B}$ activation and its signal transduction in surviving hypoxic breast cancer cells. Both from our laboratory and studies from other investigators demonstrated that clinical radiotherapy resulted in predominant activation of $\mathrm{NFKB}$ in surviving tumor cells including breast cancer cells [15-17,27-29,31,33,39]. The results presented here portraits that radiation robustly increased nuclear translocation and DNA binding activity of $\mathrm{NF}_{\mathrm{K}} \mathrm{B}$, transactivation of $53 \mathrm{NF} \mathrm{B}$ family, signaling and effector molecules and further resulted in activation of TNF $\alpha$, AKT1/2/3, SOD2 and ERK1/2 at least in surviving hypoxic breast cancer cells. A plethora of evidence has demonstrated that both AKT and ERK are upstream of $\mathrm{NF} K \mathrm{~B}$ and are actively involved in $\mathrm{NFKB}_{\mathrm{K}}$ activation. Like-wise, we have demonstrated that TNF $\alpha$ and SOD2 though are the direct downstream targets of NFkB signaling are in fact individually exerts a positive feedback input with $\mathrm{NF}_{\kappa} \mathrm{B}$ signaling that promotes robust and persistent $\mathrm{NF}_{\kappa} \mathrm{B}$ activation after radiation [33,34]. 


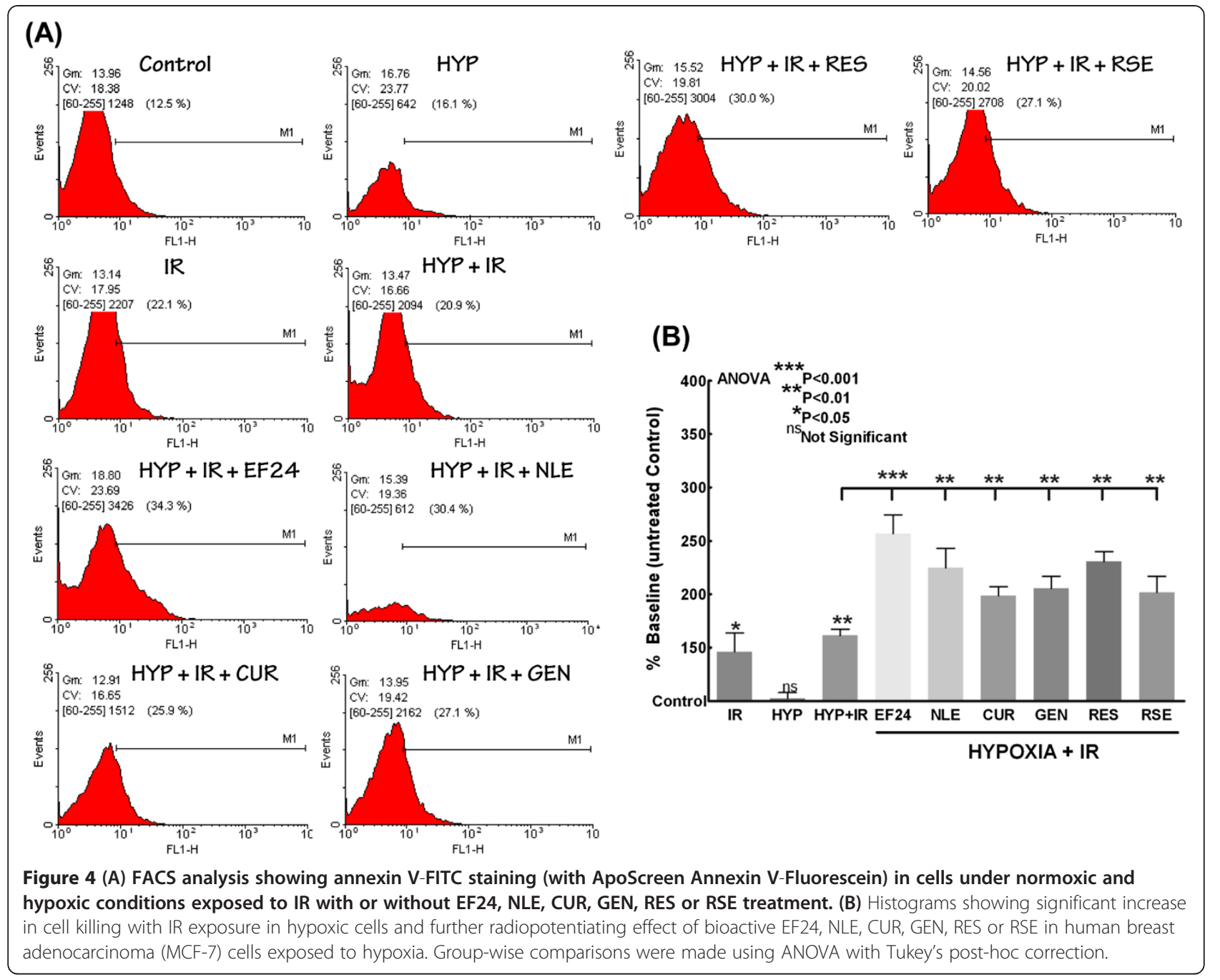

Further, this study, for the first time unveils the understanding of how the known bioactive phytochemicals NLE, CUR, GEN, RES or RSE and synthetic analogue (EF24, in this case) radio-sensitize and/or radiopotentiate hypoxic breast cancer cells. The results precisely demonstrated that phytochemicals including neem leaf extract, genistein, resveratrol, raspberry extract, curcumin and, its synthetic analogue EF24 have significant impact on attenuating radiation modulated $\mathrm{NF}_{\kappa} \mathrm{B}$ nuclear import, DNA-binding activity, signaling pathway transcriptome and on the translational activation of its signaling (TNF $\alpha$, AKT1/2/3, SOD2 and ERK1/2) and effector (Birc 1, 2, 5) proteins in surviving hypoxic breast cancer cells. To that end, the significant reverting effect (53 off 53 except NLE where it is 50/53) IR-induced transcriptional response demonstrate for the fact all these compounds converge on the NFKB signaling pathway to inhibit hypoxia induced radio-adaptation and to radio-potentiate cell killing. A simplified schematic pathway map is presented in Figure 5 in an attempt to give a glimpse of $\mathrm{NFKB}$ signaling targeted by these compounds. CUR, a dietary polyphenol derived from turmeric, Curcuma longa, is a pharmacologically safe and effective agent that has been demonstrated to have anti-inflammatory, antiproliferative, and antitumor effects by modulating many potential molecular targets (47). Because of its use as a food additive and its potential for cancer chemoprevention, curcumin has undergone extensive toxicological screening and pre-clinical investigation in rats, mice, dogs, and monkeys (48). Curcumin has been demonstrated to inhibit NFKB by suppressing the activation of IKK by interacting directly with the kinase (47). Similarly, RES, a phytoalexin present in grape skins and red wines, exerts striking inhibitory effects on diverse cellular events associated with tumor initiation, promotion, and progression [40]. A number of studies showed RES associated inhibition of $\mathrm{NFKB}_{\mathrm{K}}$ and further have dissected out that it exerts the response through (a) phosphorylation/degradation of IKB $\alpha$ via IKK [41]; (b) inhibiting IKK activity [42] or (c) phosphorylation/ 


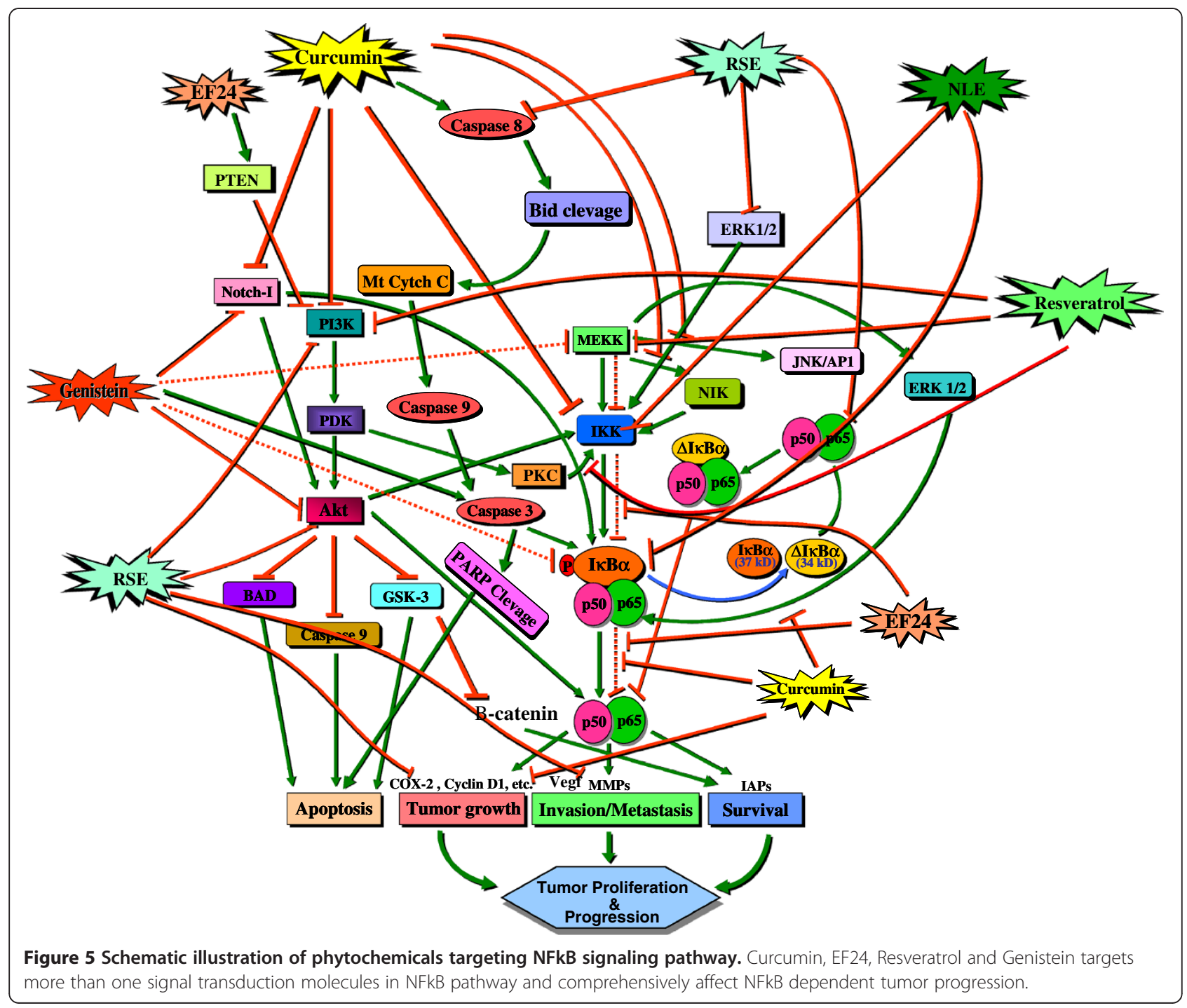

nuclear translocation of the p65 [43]. Similarly, GEN, the most abundant isoflavone found in soybeans, is believed to be a potent anticancer agent $[44,45]$ and is currently under 34 (7 studies still open) clinical trials (www.clinicaltrials.gov). Notably, NFKB inhibitory effect [46-55] radio-sensitizing effects [55-62] of Genistein have been well documented. To that end, Sarkar and colleagues suggested that Genistein inhibited MEKK1 kinase activity may be responsible for the decreased phosphorylation of I $\mathrm{B} \alpha \alpha$ and thereby result in the inactivation of NFkB [63-66]. Furthermore, synthetic analogue of curcumin, EF24 has shown to possess potent anticancer activity, both in vitro as well as in vivo [67]. More importantly, EF24 has been shown to directly inhibit IKK $\beta$ kinase activity [68]. In addition, we have recently shown that bioactive RSE and NLE selectively target radiation induced $\mathrm{NFKB}$ in surviving cancer cells and potentiate radiation induced cell death $[27,30,31]$.
In the context of the breast cancer cure, research around the globe is primarily and appropriately focused on dissecting out the potential benefit of bioactive phytochemicals. Indeed, half of the top anticancer drugs in the USA are derived directly or indirectly from natural products $[69,70]$. To that end, we and others have shown that CUR, NLE, RSE, RES, GEN possess potent antibreast cancer properties by modulating many potential molecular targets and thereby exerts breast cancer cell killing, prevent tumor growth, invasion and metastasis [27]. Interestingly, studies have shown that at least in part, the benefits of these phytochemicals are imparted by selectively targeting $\mathrm{NFKB}$ in breast cancer cells [71-75]. However, as discussed above, hypoxia is a frequent phenomenon in breast cancer, orchestrated as a result of tumor outgrowing the existing vasculature leading to an adaptive response. Radiation as one of the prime treatment modality for breast cancer, hypoxia 
significantly affects the radio-therapeutic ratio in breast cancer. Our result in the present study has shown that the cellular response of hypoxia is modulated by the ubiquitous transcription factor NFKB. Besides the fact that hypoxia affects general radio-sensitization processes such as apoptosis and proliferation, our data linked hypoxia associated $\mathrm{NF} K \mathrm{~B}$ activation to the radio-protective phenotype in breast cancer cells. Exquisitely, the data presented here demonstrated the potential of CUR, EF24, NLE, RSE, RES and GEN in targeting not only radiation-induced $\mathrm{NF} \kappa \mathrm{B}$ activation but also $\mathrm{NF} \kappa \mathrm{B}$ signal transduction and downstream NFKB dependent translational/functional response. Though a lot need to be explored on response initiation signaling and molecular mechanism(s) upstream of NFKB by these phytochemicals, this study, per se ostensibly identified that curcumin, its analogue EF24, genistein, resveratrol, raspberry extract and neem leaf extract converge on selective inhibition of $\mathrm{NFKB}$ signaling and thereby potentiates radiotherapy in hypoxic breast cancer cells. Further studies delineating the drug and radiation dose, functional downstream molecular (effector) orchestration, pre-clinical efficacy with appropriate animal models, multi-compound combinatorial synergism, if any, are warranted and are currently pursued in our laboratory.

\section{Conclusions}

In this study, we investigated the effects of CUR, curcumin analog EF24, NLE, GEN, RES and RSE on the NFKB DNA-binding activity and NFKB signal transduction in hypoxic breast cancer cells exposed to IR. Furthermore, we elucidated the effects of these bioactives in the activation and cellular localization of hypoxiaresponsive $\mathrm{NF} \kappa \mathrm{B}$ related effectors including p53, Akt, Nos3, Erk1/2, SOD2, p50, p65, TNF $\alpha$, IAP1, IAP2 and Survivin. More importantly, we elucidated the efficacy of these compounds in potentiating IR induced hypoxic cell killing in this setting. In hypoxic breast cancer cells, CUR, EF24, NLE, GEN, RES and RSE resulted in a (i) a complete suppression of IR-induced NFKB-DNA binding activity (ii) attenuation of IR-induced NFKB signal transduction and target transcriptome, (iii) mitigation of IRinduced Akt,, Nos3, Erk1/2, SOD2, p50, p65, TNF $\alpha$, Birc 1,2 and 5 and (iv) potentiates IR-induced cell killing, implying that these bioactive phytochemicals may play a key role in regulating $\mathrm{NFK}_{\mathrm{K}} \mathrm{B}$ signaling pathway dependent 'hypoxic processes' and may potentiate $\mathrm{R} T$ in this setting.

\section{Competing interests}

The authors declare that they have no competing interests.

\section{Authors' contributions}

SA carried out the molecular assays and helped to draft the manuscript. MN participated in the design of the study and performed the statistical analysis. TSH participated in the design of the study and helped to draft the manuscript. VA carried out the EF24 synthesis, NLE and RSE characterization. NA conceived the study, and participated in its design and coordination and drafted the manuscript. All authors read and approved the final manuscript.

\section{Acknowledgements}

The authors are supported by National Institutes of Health (COBRE-P20-PAR09-079-PJI) and American Cancer Society (Grant ACS-IRG-05-066-01) to N. Aravindan; and by National Aeronautics and Space Administration (NASA) Ground- Based Studies in Space Radiobiology, Grant NNX12- AC32G to M. Natarajan.

\section{Author details}

${ }^{1}$ Department of Radiation Oncology, University of Oklahoma Health Sciences Center, Oklahoma City, OK, USA. ²Department of Pathology, University of Texas Health Sciences Center, San Antonio, TX, USA. ${ }^{3}$ Department of Pharmaceutical Sciences, University of Oklahoma Health Sciences Center, 800 NE 10th Street, Oklahoma City, OK, USA.

Received: 26 June 2012 Accepted: 25 February 2013

Published: 4 March 2013

\section{Reference}

1. Nordsmark M, Bentzen SM, Rudat V, Brizel D, Lartigau E, Stadler P, Becker A, Adam M, Molls M, Dunst J, et al: Prognostic value of tumor oxygenation in 397 head and neck tumors after primary radiation therapy. An international multi-center study. Radiother Oncol 2005, 77:18-24.

2. Fyles A, Milosevic M, Hedley D, Pintilie M, Levin W, Manchul L, Hill RP: Tumor hypoxia has independent predictor impact only in patients with node-negative cervix cancer. J Clin Oncol 2002, 20:680-687.

3. Ruan K, Song G, Ouyang G: Role of hypoxia in the hallmarks of human cancer. J Cell Biochem 2009, 107:1053-1062.

4. Gatenby RA, Kessler HB, Rosenblum JS, Coia LR, Moldofsky PJ, Hartz WH, Broder GJ: Oxygen distribution in squamous cell carcinoma metastases and its relationship to outcome of radiation therapy. Int J Radiat Oncol Biol Phys 1988, 14:831-838.

5. Hockel M, Schlenger K, Aral B, Mitze M, Schaffer U, Vaupel P: Association between tumor hypoxia and malignant progression in advanced cancer of the uterine cervix. Cancer Res 1996, 56:4509-4515.

6. Brizel DM, Sibley GS, Prosnitz LR, Scher RL, Dewhirst MW: Tumor hypoxia adversely affects the prognosis of carcinoma of the head and neck. Int J Radiat Oncol Biol Phys 1997, 38:285-289.

7. Okunieff $P$, Hoeckel M, Dunphy EP, Schlenger K, Knoop C, Vaupel P: Oxygen tension distributions are sufficient to explain the local response of human breast tumors treated with radiation alone. Int J Radiat Oncol Biol Phys 1993, 26:631-636.

8. Lundgren $\mathrm{K}$, Holm C, Landberg G: Hypoxia and breast cancer: prognostic and therapeutic implications. Cell Mol Life Sci 2007, 64:3233-3247.

9. Vaupel P, Schlenger $K$, Knoop C, Hockel M: Oxygenation of human tumors: evaluation of tissue oxygen distribution in breast cancers by computerized O2 tension measurements. Cancer Res 1991, 51:3316-3322.

10. Hohenberger P, Felgner C, Haensch W, Schlag PM: Tumor oxygenation correlates with molecular growth determinants in breast cancer. Breast Cancer Res Treat 1998, 48:97-106.

11. Overgaard J: Hypoxic radiosensitization: adored and ignored. J Clin Oncol 2007, 25:4066-4074.

12. Bendinelli P, Matteucci E, Maroni P, Desiderio MA: NF-kappaB activation, dependent on acetylation/deacetylation, contributes to HIF-1 activity and migration of bone metastatic breast carcinoma cells. Mol Cancer Res 2009, 7:1328-1341.

13. Tafani M, Schito L, Pellegrini L, Villanova L, Marfe G, Anwar T, Rosa R, Indelicato M, Fini M, Pucci B, Russo MA: Hypoxia-increased RAGE and P2X7R expression regulates tumor cell invasion through phosphorylation of Erk1/2 and Akt and nuclear translocation of NF-\{kappa\}B. Carcinogenesis 2011, 32:1167-1175.

14. Zhou D, Brown SA, Yu T, Chen G, Barve S, Kang BC, Thompson JS: A high dose of ionizing radiation induces tissue-specific activation of nuclear factor-kappaB in vivo. Radiat Res 1999, 151:703-709.

15. Aravindan N, Madhusoodhanan R, Ahmad S, Johnson D, Herman TS: Curcumin inhibits NFkappaB mediated radioprotection and modulate apoptosis related genes in human neuroblastoma cells. Cancer Biol Ther 2008, 7:569-576. 
16. Madhusoodhanan R, Natarajan M, Veeraraghavan J, Herman TS, Aravindan $\mathrm{N}$ : NFkappaB activity and transcriptional responses in human breast adenocarcinoma cells after single and fractionated irradiation. Cancer Biol Ther 2009, 8:765-773.

17. Madhusoodhanan R, Natarajan M, Veeraraghavan J, Herman TS, Jamgade A, Singh N, Aravindan N: NFkappaB signaling related molecular alterations in human neuroblastoma cells after fractionated irradiation. J Radiat Res 2009, 50:311-324.

18. Baeuerle PA, Baltimore D: Hormonal Control Regulation of Gene Transcription. In Molecular Aspects of Cellular Regulation. Edited by Cohen P, Foulkes JG. North Holland, Amsterdam: Elsevier/ North Holland Biomedical Press Amsterdam; 1991:409-432.

19. Lenardo MJ, Baltimore D: NF-kappa B: a pleiotropic mediator of inducible and tissue-specific gene control. Cell 1989, 58:227-229.

20. Neri A, Chang CC, Lombardi L, Salina M, Corradini P, Maiolo AT, Chaganti RS, Dalla-Favera R: B cell lymphoma-associated chromosomal translocation involves candidate oncogene lyt-10, homologous to NF-kappa B p50. Cell 1991, 67:1075-1087.

21. Higgins KA, Perez JR, Coleman TA, Dorshkind K, McComas WA, Sarmiento UM, Rosen CA, Narayanan R: Antisense inhibition of the p65 subunit of NF-kappa B blocks tumorigenicity and causes tumor regression. Proc Natl Acad Sci U S A 1993, 90:9901-9905.

22. Tozawa K, Sakurada S, Kohri K, Okamoto T: Effects of anti-nuclear factor kappa $B$ reagents in blocking adhesion of human cancer cells to vascular endothelial cells. Cancer Res 1995, 55:4162-4167.

23. Ahmed KM, Li JJ: NF-kappa B-mediated adaptive resistance to ionizing radiation. Free Radic Biol Med 2008, 44:1-13.

24. McBride WH, Pajonk F, Chiang CS, Sun JR: NF-kappa B, cytokines, proteasomes, and low-dose radiation exposure. Mil Med 2002, 167:66-67.

25. Natarajan M, Mohan S, Konopinski R, Otto RA, Herman TS: Induced telomerase activity in primary aortic endothelial cells by low-LET gamma-radiation is mediated through NF-kappaB activation. Br J Radiol 2008, 81:711-720.

26. Sen P, Chakraborty PK, Raha S: Activation of p38MAPK by repetitive lowgrade oxidative stress leads to pro-survival effects. Biochim Biophys Acta 2007, 1773:367-374.

27. Madhusoodhanan R, Natarajan M, Singh JV, Jamgade A, Awasthi V, Anant S, Herman TS, Aravindan N: Effect of black raspberry extract in inhibiting NFkappa B dependent radioprotection in human breast cancer cells. Nutr Cancer 2010, 62:93-104.

28. Veeraraghavan J, Natarajan M, Herman TS, Aravindan N: Curcumin-altered p53-response genes regulate radiosensitivity in p53-mutant Ewing's sarcoma cells. Anticancer Res 2010, 30:4007-4015.

29. Aravindan N, Veeraraghavan J, Madhusoodhanan R, Herman TS, Natarajan M: Curcumin regulates low-linear energy transfer gamma-radiation-induced NFkappaB-dependent telomerase activity in human neuroblastoma cells. Int J Radiat Oncol Biol Phys 2011, 79:1206-1215

30. Veeraraghavan J, Aravindan S, Natarajan M, Awasthi V, Herman TS, Aravindan N: Neem leaf extract induces radiosensitization in human neuroblastoma xenograft through modulation of apoptotic pathway. Anticancer Res 2011, 31:161-170.

31. Veeraraghavan J, Natarajan M, Lagisetty $P$, Awasthi $V$, Herman TS, Aravindan N: Impact of curcumin, raspberry extract, and neem leaf extract on rel proteinregulated cell death/radiosensitization in pancreatic cancer cells. Pancreas 2011, 40:1107-1119.

32. Vilekar P, Awasthi S, Natarajan A, Anant S, Awasthi V: EF24 suppresses maturation and inflammatory response in dendritic cells. Int Immunol 2012, 24:455-464.

33. Veeraraghavan J, Natarajan M, Aravindan S, Herman TS, Aravindan N: Radiation-triggered tumor necrosis factor (TNF) alpha-NFkappaB crosssignaling favors survival advantage in human neuroblastoma cells. J Biol Chem 2011, 286:21588-21600.

34. Veeraraghavan J, Natarajan M, Herman TS, Aravindan N: Low-dose gammaradiation-induced oxidative stress response in mouse brain and gut: regulation by NFkappaB-MnSOD cross-signaling. Mutat Res 2011, 718:44-55.

35. Bristow RG, Hill RP: Hypoxia and metabolism. Hypoxia, DNA repair and genetic instability. Nat Rev Cancer 2008, 8:180-192.

36. Tang ZN, Zhang F, Tang P, Qi XW, Jiang J: Hypoxia induces RANK and RANKL expression by activating HIF-1alpha in breast cancer cells. Biochem Biophys Res Commun 2011, 408:411-416.

37. Royds JA, Dower SK, Qwarnstrom EE, Lewis CE: Response of tumour cells to hypoxia: role of p53 and NFkB. Mol Pathol 1998, 51:55-61.
38. Koong AC, Chen EY, Giaccia AJ: Hypoxia causes the activation of nuclear factor kappa B through the phosphorylation of I kappa B alpha on tyrosine residues. Cancer Res 1994, 54:1425-1430.

39. Aravindan N, Madhusoodhanan R, Natarajan M, Herman TS: Alteration of apoptotic signaling molecules as a function of time after radiation in human neuroblastoma cells. Mol Cell Biochem 2008, 310:167-179.

40. Jang M, Cai L, Udeani GO, Slowing KV, Thomas CF, Beecher CW, Fong HH, Farnsworth NR, Kinghorn AD, Mehta RG, et al: Cancer chemopreventive activity of resveratrol, a natural product derived from grapes. Science 1997, 275:218-220.

41. Tsai SH, Lin-Shiau SY, Lin JK: Suppression of nitric oxide synthase and the down-regulation of the activation of NFkappaB in macrophages by resveratrol. Br J Pharmacol 1999, 126:673-680.

42. Holmes-McNary M, Baldwin AS Jr: Chemopreventive properties of transresveratrol are associated with inhibition of activation of the IkappaB kinase. Cancer Res 2000, 60:3477-3483.

43. Manna SK, Mukhopadhyay A, Aggarwal BB: Resveratrol suppresses TNFinduced activation of nuclear transcription factors NF-kappa B, activator protein-1, and apoptosis: potential role of reactive oxygen intermediates and lipid peroxidation. J Immunol 2000, 164:6509-6519.

44. Knight DC, Eden JA: A review of the clinical effects of phytoestrogens. Obstet Gynecol 1996, 87:897-904.

45. Mills PK, Beeson WL, Phillips RL, Fraser GE: Cohort study of diet, lifestyle, and prostate cancer in Adventist men. Cancer 1989, 64:598-604.

46. Ali S, Varghese L, Pereira L, Tulunay-Ugur OE, Kucuk O, Carey TE, Wolf GT, Sarkar FH: Sensitization of squamous cell carcinoma to cisplatin induced killing by natural agents. Cancer Lett 2009, 278:201-209.

47. Alonso V, Perez-Martinez FC, Calahorra FJ, Esbrit P: Phytoestrogen modulation of bone-related cytokines and its impact on cell viability in human prostate cancer cells. Life Sci 2009, 85:421-430

48. Banerjee S, Li Y, Wang Z, Sarkar FH: Multi-targeted therapy of cancer by genistein. Cancer Lett 2008, 269:226-242.

49. Baxa DM, Yoshimura FK: Genistein reduces NF-kappa B in T lymphoma cells via a caspase-mediated cleavage of I kappa B alpha. Biochem Pharmacol 2003, 66:1009-1018.

50. Dijsselbloem N, Goriely S, Albarani V, Gerlo S, Francoz S, Marine JC, Goldman M, Haegeman G: Vanden Berghe W: A critical role for p53 in the control of NF-kappaB-dependent gene expression in TLR4-stimulated dendritic cells exposed to Genistein. J Immunol 2007, 178:5048-5057.

51. Gadgeel SM, Ali S, Philip PA, Wozniak A, Sarkar FH: Genistein enhances the effect of epidermal growth factor receptor tyrosine kinase inhibitors and inhibits nuclear factor kappa B in nonsmall cell lung cancer cell lines. Cancer 2009, 115:2165-2176.

52. Gong L, Li Y, Nedeljkovic-Kurepa A, Sarkar FH: Inactivation of NF-kappaB by genistein is mediated via Akt signaling pathway in breast cancer cells. Oncogene 2003, 22:4702-4709.

53. Karmakar S, Roy Choudhury S, Banik NL, Ray SK: Combination of N-(4hydroxyphenyl) retinamide and genistein increased apoptosis in neuroblastoma SK-N-BE2 and SH-SY5Y xenografts. Neuroscience 2009, 163:286-295.

54. Li Z, Li J, Mo B, Hu C, Liu H, Qi H, Wang X, Xu J: Genistein induces cell apoptosis in MDA-MB-231 breast cancer cells via the mitogen-activated protein kinase pathway. Toxicol In Vitro 2008, 22:1749-1753.

55. Singh-Gupta V, Zhang H, Banerjee S, Kong D, Raffoul JJ, Sarkar FH, Hillman GG: Radiation-induced HIF-1alpha cell survival pathway is inhibited by soy isoflavones in prostate cancer cells. Int J Cancer 2009, 124:1675-1684.

56. Garg AK, Buchholz TA, Aggarwal BB: Chemosensitization and radiosensitization of tumors by plant polyphenols. Antioxid Redox Signal 2005, 7:1630-1647

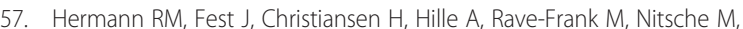
Grundker C, Viereck V, Jarry H, Schmidberger H: Radiosensitization dependent on p53 function in bronchial carcinoma cells by the isoflavone genistein and estradiol in vitro. Strahlenther Onkol 2007 183:195-202.

58. Katz J, Blake E, Medrano TA, Sun Y, Shiverick KT: Isoflavones and gamma irradiation inhibit cell growth in human salivary gland cells. Cancer Lett 2008, 270:87-94

59. Raffoul JJ, Wang Y, Kucuk O, Forman JD, Sarkar FH, Hillman GG: Genistein inhibits radiation-induced activation of NF-kappaB in prostate cancer cells promoting apoptosis and G2/M cell cycle arrest. BMC Cancer 2006, 6:107. 
60. Ravindranath $\mathrm{MH}$, Muthugounder S, Presser N, Viswanathan S: Anticancer therapeutic potential of soy isoflavone, genistein. Adv Exp Med Biol 2004 546:121-165.

61. Shin JI, Shim JH, Kim KH, Choi HS, Kim JW, Lee HG, Kim BY, Park SN, Park OJ, Yoon DY: Sensitization of the apoptotic effect of gamma-irradiation in genistein-pretreated CaSki cervical cancer cells. J Microbiol Biotechnol 2008, 18:523-531.

62. Wang Y, Raffoul JJ, Che M, Doerge DR, Joiner MC, Kucuk O, Sarkar FH, Hillman GG: Prostate cancer treatment is enhanced by genistein in vitro and in vivo in a syngeneic orthotopic tumor model. Radiat Res 2006 $166: 73-80$.

63. El-Rayes BF, Ali S, Ali IF, Philip PA, Abbruzzese J, Sarkar FH: Potentiation of the effect of erlotinib by genistein in pancreatic cancer: the role of Akt and nuclear factor-kappaB. Cancer Res 2006, 66:10553-10559.

64. Sarkar FH, Li Y: Mechanisms of cancer chemoprevention by soy isoflavone genistein. Cancer Metastasis Rev 2002, 21:265-280.

65. Sarkar FH, Li Y: Soy isoflavones and cancer prevention. Cancer Invest 2003, $21: 744-757$

66. Sarkar $\mathrm{FH}, \mathrm{Li}$ Y: The role of isoflavones in cancer chemoprevention. Front Biosci 2004, 9:2714-2724.

67. Subramaniam D, May R, Sureban SM, Lee KB, George R, Kuppusamy $P$, Ramanujam RP, Hideg K, Dieckgraefe BK, Houchen CW, Anant S: Diphenyl difluoroketone: a curcumin derivative with potent in vivo anticancer activity. Cancer Res 2008, 68:1962-1969.

68. Kasinski AL, Du Y, Thomas SL, Zhao J, Sun SY, Khuri FR, Wang CY, Shoji M, Sun A, Snyder JP, et al: Inhibition of IkappaB kinase-nuclear factor-kappaB signaling pathway by 3,5-bis(2-flurobenzylidene)piperidin-4-one (EF24), a novel monoketone analog of curcumin. Mol Pharmacol 2008, 74:654-661.

69. Schmidt BM, Ribnicky DM, Lipsky PE, Raskin I: Revisiting the ancient concept of botanical therapeutics. Nat Chem Biol 2007, 3:360-366.

70. Newman DJ, Cragg GM: Natural products as sources of new drugs over the last 25 years. J Nat Prod 2007, 70:461-477.

71. Zong H, Wang F, Fan QX, Wang LX: Curcumin inhibits metastatic progression of breast cancer cell through suppression of urokinase-type plasminogen activator by NF-kappa B signaling pathways. Mol Biol Rep 2012, 39:4803-4808.

72. Liu Q, Loo WT, Sze SC, Tong Y: Curcumin inhibits cell proliferation of MDA-MB-231 and BT-483 breast cancer cells mediated by downregulation of NFkappaB, cyclinD and MMP-1 transcription. Phytomedicine 2009, 16:916-922.

73. Pozo-Guisado E, Merino JM, Mulero-Navarro S, Lorenzo-Benayas MJ, Centeno F, Alvarez-Barrientos A, Fernandez-Salguero PM: Resveratrolinduced apoptosis in MCF-7 human breast cancer cells involves a caspase-independent mechanism with downregulation of $\mathrm{BCl}-2$ and NF-kappaB. Int J Cancer 2005, 115:74-84.

74. Seo HS, Choi HS, Choi HS, Choi YK, Um JY, Choi I, Shin YC, Ko SG: Phytoestrogens induce apoptosis via extrinsic pathway, inhibiting nuclear factor-kappaB signaling in HER2-overexpressing breast cancer cells. Anticancer Res 2011, 31:3301-3313.

75. Valachovicova T, Slivova V, Bergman H, Shuherk J, Sliva D: Soy isoflavones suppress invasiveness of breast cancer cells by the inhibition of NF-kappaB/AP-1-dependent and -independent pathways. Int J Oncol 2004, 25:1389-1395.

doi:10.1186/1748-717X-8-46

Cite this article as: Aravindan et al:: Molecular basis of 'hypoxic' breast cancer cell radio-sensitization: phytochemicals converge on radiation induced Rel signaling. Radiation Oncology 2013 8:46.

\section{Submit your next manuscript to BioMed Central and take full advantage of:}

- Convenient online submission

- Thorough peer review

- No space constraints or color figure charges

- Immediate publication on acceptance

- Inclusion in PubMed, CAS, Scopus and Google Scholar

- Research which is freely available for redistribution 